\title{
Design of an Embedded Broadband Thermoelectric Power Sensor in the InP DHBT Process ${ }^{+}$
}

\author{
Shiqi Ma *, Wolfgang Heinrich and Viktor Krozer \\ Ferdinand-Braun-Institut, Leibniz-Institut für Höchstfrequenztechnik (FBH), 12489 Berlin, Germany; \\ email1@gmail.com (W.H.); email1@gmail.com (V.K.) \\ * Correspondence: Shiqi.Ma@FBH-Berlin.de; Tel.: +49-0179-483-8721 \\ + Presented at the 7th International Electronic Conference on Sensors and Applications, 15-30 November \\ 2020; Available online: https://ecsa-7.sciforum.net/.
}

Published: 15 November 2020

\begin{abstract}
The thermopile-based thermoelectric sensor has emerged as an important approach for microwave power measurement. It employs the Seebeck effect, which converts the microwave power into the heat and generates the thermovoltage. However, the output thermovoltage generally exhibits the feature of frequency-dependent, which affects measurement accuracy. Besides, the low sensitivity of the current existed planar thermopile-based sensor constrains its further application. This is mainly caused by the heat loss of the substrate in the conversion process of microwave power-heat-electricity. In this paper, a novel embedded power sensor based on the InP DHBT process is presented. The thermopile is embedded in the benzocyclobutene (BCB) to prevent the heat loss, the embedded structure also enables this sensor to eliminate the need for microelectromechanical system (MEMS) technology. The electromagnetic simulation by ANSYS HFSS and thermal simulation by ANSYS Steady-State Thermal are combined to evaluate the sensor performance. The result shows that the output voltage increases with the input power linearly, and the proposed sensor is almost independent of the microwave frequency. A sensitivity of 1.07 $\mathrm{mV} / \mathrm{mW}$ has been achieved up to $200 \mathrm{GHz}$, with the port return loss lower than $-15.8 \mathrm{~dB}$.
\end{abstract}

Keywords: thermoelectric power sensor; embedded; MMIC; broadband

\section{Introduction}

Microwave power measurement plays an indispensable role in wireless communication. At present, there are many alternative sensor types are available for power detection, such as thermoelectric sensor, thermistor sensor, diode sensor, and so on [1]. Among these different approaches, the thermoelectric sensor arises with advantages of passive operation (no need for bias supply), excellent linearity, high dynamic range, broadband performance, and remarkably, compatibility with monolithic microwave integrated circuit (MMIC) technology. One of the promising topics to be investigated is measuring the power delivered from an MMIC amplifier directly on-chip, which has the advantages of low insertion loss, low-cost fabrication, and continuous power monitoring as well. These merits give it a wide variety of uses, such as gain control and circuit protection.

The first termination-type thermoelectric power sensor with an MMIC process based on the Seebeck effect was introduced in 1996 [2], which indirectly measuring the power dissipated on 50 ohms load. After that, to improve the sensitivity, a thermoelectric microwave power sensor by bulk etching MEMS technology was presented [3]. A cavity was etched from the back of the substrate, under the thermopile and resistors. But the realization of MEMS technology increases the cost and difficulty of the following package. Moreover, a sandwich-type power sensor was proposed, where 
a simple $\mathrm{Si}_{3} \mathrm{~N}_{4}$ dielectric layer takes the place of the back cavity by MEMS technology [4]. However, the improvement of sensitivity is not enough, and thus limiting its performance and further application.

To further increasing the sensitivity, the embedded sensor structure in the InP DHBT process was designed. The very low thermal conductivity of $\mathrm{BCB}$ ensures heat preservation around the thermopile as much as possible, which leads to a reduced heat loss. Comparing to other techniques, this method has the advantage of wide frequency range and high sensitivity. What's more, the cost and complexity of the process will be reduced without the need for MEMS. To the best of the author's knowledge, there is no literature about such a thermoelectric power sensor that fully compatible with the InP DHBT process at Ferdinand-Braun-Institute (FBH) so far.

\section{Principle and Modeling}

A thermocouple is composed of two dissimilar materials. When there is a temperature difference between the two ends, according to the Seebeck Effect, the thermocouple converts the temperature difference proportional to the voltage difference. Several series-connected thermocouples make up the thermopile, to superpose thermovoltage of each thermocouple $[5,6]$. The Seebeck voltage can be obtained as:

$$
V_{\text {seebeck }}=\left(\alpha_{a}-\alpha_{b}\right) \cdot \sum_{i}^{N}\left(T_{\text {hot }}-T_{\text {cold }}\right)
$$

where $\alpha_{a}$ and $\alpha_{b}$ are the Seebeck coefficients of the two dissimilar materials, $T_{\text {hot }}$ and $T_{\text {cold }}$ are the temperatures of the hot and cold ends, respectively, and $n$ is the number of the cascaded thermocouples. Therefore, the sensitivity of the proposed sensor is represented as:

$$
\mathrm{S}=V_{\text {seebeck }} / P_{\text {in }}
$$

Here $P_{\text {in }}$ is the input power.

The proposed power sensor is designed in the InP DHBT MMIC process [7], the simplified layer stack is shown in Figure 1.

- $\quad$ Three gold metal layers are embedded in BCB, including G1 $(1.5 \mu \mathrm{m})$, G2 $(4.5 \mu \mathrm{m})$, and GD (2.5 $\mu \mathrm{m})$ that serves respectively as interconnects, microstrip line, and the ground plane.

- The thickness of nickel-chrome (NiCr) thin-film resistors (TFRs) is $44 \mathrm{~nm}$, with a sheet resistance on $25 \Omega / \mathrm{sq}$ [8].

- The 15 thermocouples consist of G1 metal and $30 \mathrm{~nm}$ P-In0.53Ga0.47As. The P-In0.53Ga0.47As locates at the B1 layer with a doping level of $5 \times 10^{19} \mathrm{~cm}^{-3}$. The corresponding Seebeck coefficient is calculated based on [9]. 


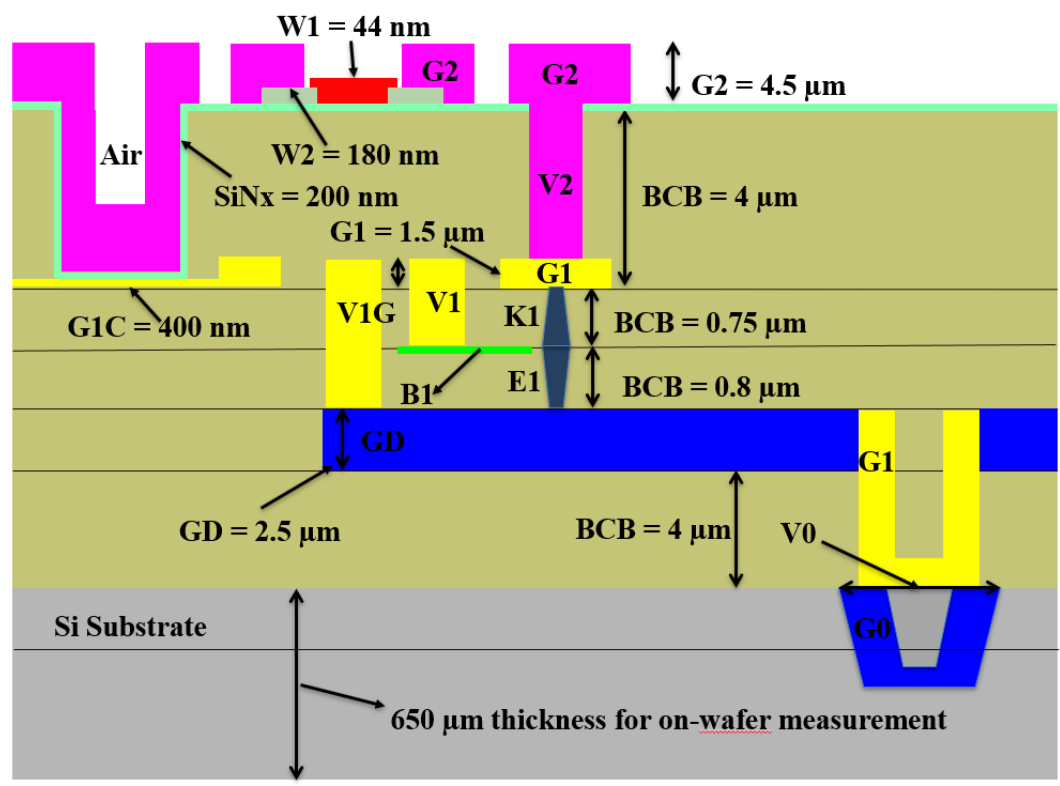

Figure 1. Layer description of the InP DHBT MMIC process.

The geometry of the embedded thermoelectric power sensor is shown in Figure $2 a$. Figure $2 b$ gives the detailed dimension parameters of the proposed sensor. The microwave power is fed-in by the RF pad and then dissipated on the two $100 \Omega \mathrm{NiCr}$ TFRs that are connected in parallel. The size of the selected TFR is $10 \mu \mathrm{m} \times 40 \mu \mathrm{m}$.

The generated Joule heat transfer to surroundings by the means of heat conduction, convection and, radiation. When a steady state has reached, a heat distribution of the embedded thermoelectric power sensor emerges, which leads to a temperature difference along the thermopile. Finally, the generated thermovoltage is measured by the DC pad.

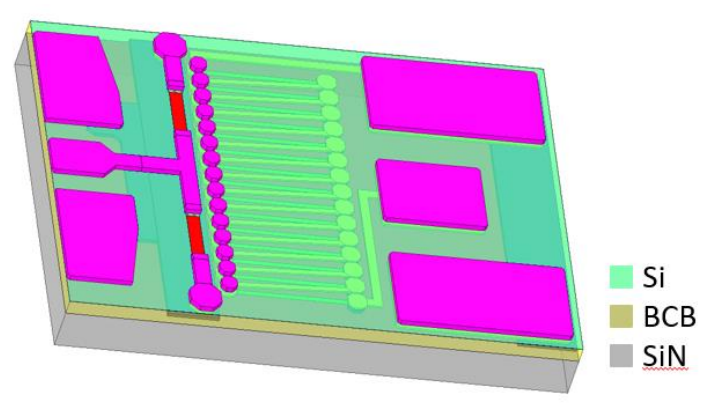

(a)

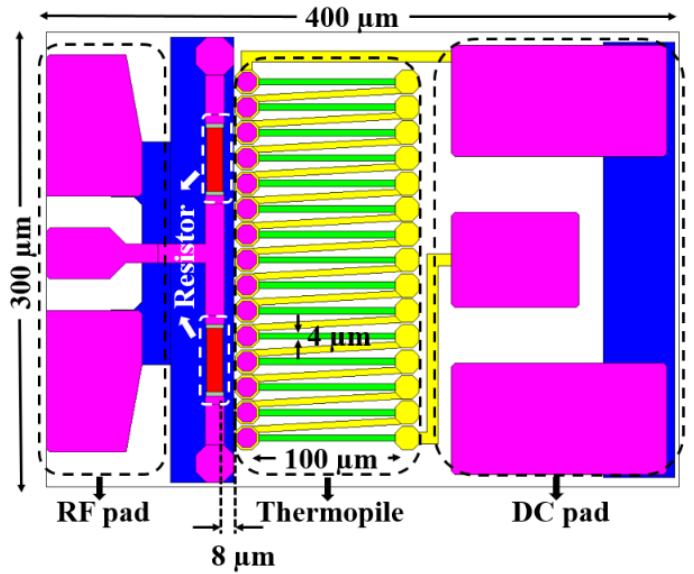

(b)

Figure 2. (a) Schematic overview of the proposed sensor; (b) Dimension parameters of the proposed sensor.

The thermal parameters used in the simulation are illustrated in Table 1.

Table 1. Parameters in the electro-thermal simulation.

\begin{tabular}{cc}
\hline Parameter & Value \\
\hline Thermal conductivity $(\mathrm{Au})$ & $315 \mathrm{~W} /(\mathrm{m} \cdot \mathrm{k})$ \\
Thermal conductivity $(\mathrm{BCB})$ & $0.29 \mathrm{~W} /(\mathrm{m} \cdot \mathrm{k})$ \\
Thermal conductivity $(\mathrm{SiN})$ & $30 \mathrm{~W} /(\mathrm{m} \cdot \mathrm{k})$
\end{tabular}




\begin{tabular}{cc} 
Seebeck coefficient (Au) & $1.5 \mu \mathrm{V} / \mathrm{K}$ \\
Seebeck coefficient (In0.53Ga0.47As) & $90 \mu \mathrm{V} / \mathrm{K}$ \\
Ambient temperature & $300 \mathrm{~K}$ \\
\hline
\end{tabular}

\section{Simulation Result}

The port reflection performance of the embedded power sensor that simulated by ANSYS HFSS is given in Figure 3, the return loss is lower than $-15.8 \mathrm{~dB}$ up to $200 \mathrm{GHz}$. Less than $2.6 \%$ of the power is reflected.

Next, the electromagnetic result from ANSYS HFSS is imported to ANSYS Steady-State Thermal component to obtain the thermal result. As in Figure 4a, given $10 \mathrm{~mW}$ input power at $20 \mathrm{GHz}$, the two TFRs have the highest temperature of $349.82 \mathrm{~K}$. The temperature at the hot end/cold end of each thermocouple is shown in Figure $4 \mathrm{~b}$.

According to the Equation (1), the calculated output voltages with $10 \mathrm{~mW}$ to $100 \mathrm{~mW}$ input power are shown in Figure 5a. The sensitivities versus frequency from $10 \mathrm{GHz}$ to $200 \mathrm{GHz}$ are calculated by Equation (2), as shown in Figure $5 \mathrm{~b}$.

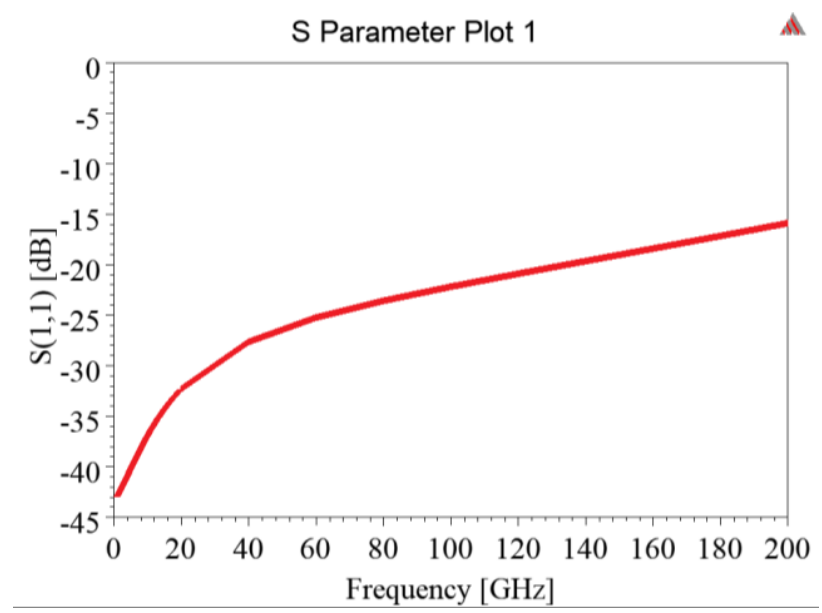

Figure 3. The simulated return loss of the proposed sensor.

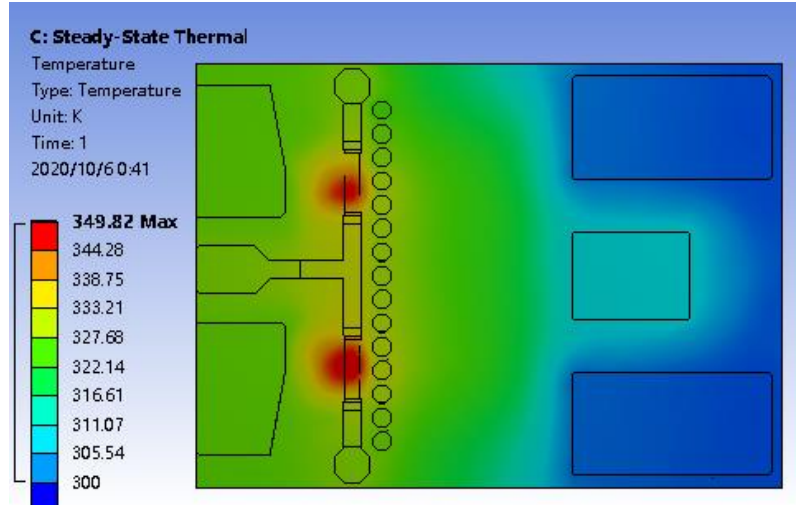

(a)

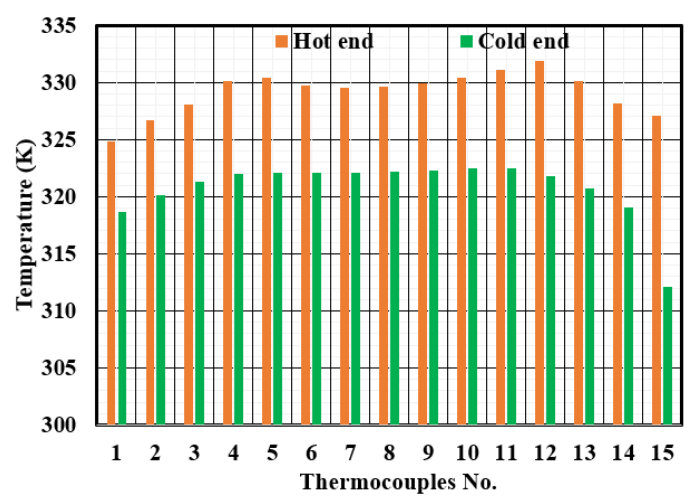

(b)

Figure 4. When given $10 \mathrm{~mW}$ input at $20 \mathrm{GHz}$ : (a) Temperature distribution in the sensor chip; (b) Temperature at the hot end/cold end of each thermocouple. 


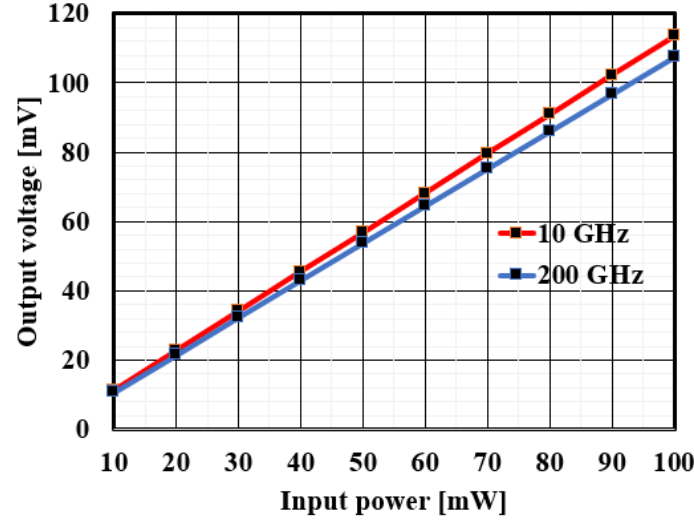

(a)

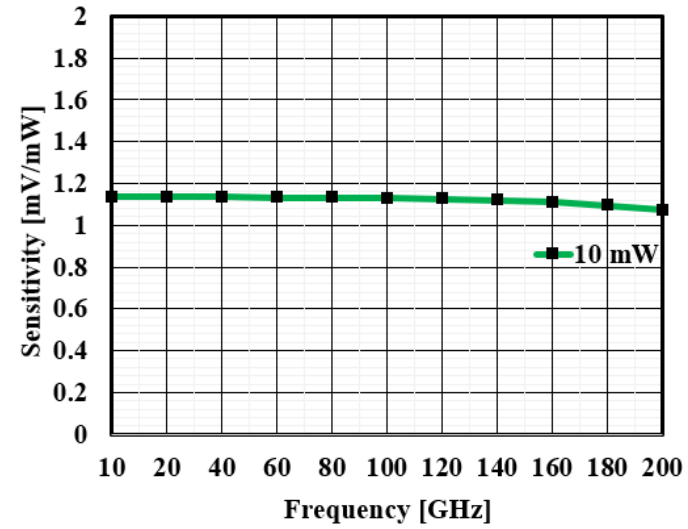

(b)

Figure 5. (a) Output voltage versus input power from $10 \mathrm{~mW}$ to $100 \mathrm{~mW}$; (b) Under $10 \mathrm{~mW}$ input power, the sensitivity versus frequency between $10 \mathrm{GHz}$ and $200 \mathrm{GHz}$.

The output voltages increase with input power linearly, there is a very slight drop when the frequency increases from $10 \mathrm{GHz}$ to $200 \mathrm{GHz}$. Given a $10 \mathrm{~mW}$ input power, the sensitivities of the power sensor are $1.14 \mathrm{mV} / \mathrm{mW}$ at $10 \mathrm{GHz}$ and $1.07 \mathrm{mV} / \mathrm{mW}$ at $200 \mathrm{GHz}$. It can be concluded that the proposed sensor almost shows the frequency-independent characteristic.

Table 2 gives the comparison of thermoelectric power sensors based on different technology, it is apparent that the embedded thermoelectric power sensor provides better sensitivity and wider working frequency. Also, the proposed sensor achieves low-cost fabrication without MEMS.

Table 2. Comparison of the different thermoelectric power sensor.

\begin{tabular}{ccccc}
\hline & This Work & [2] & [3] & [4] \\
\hline Sensitivity (mV/mW) & $1.14 @ 10 \mathrm{GHz}$ & $0.55 @ 10 \mathrm{GHz}$ & $0.27 @ 10 \mathrm{GHz}$ & $0.09 @ 10 \mathrm{GHz}$ \\
Frequency Range & $\mathrm{Up}$ to $200 \mathrm{GHz}$ & $\mathrm{Up}$ to $26 \mathrm{GHz}$ & $\mathrm{Up}$ to $10 \mathrm{GHz}$ & $\mathrm{Up}$ to $20 \mathrm{GHz}$ \\
Need of MEMS & $\mathrm{No}$ & No & Yes & No \\
\hline
\end{tabular}

\section{Discussion}

In this work, a design of the embedded broadband thermoelectric power sensor in the InP DHBT process is presented. The electromagnetic simulation by HFSS and thermal simulation by Steadystate thermal are combined to obtain an accurate result. The proposed sensor can measure power directly on-chip with minimum impact on the system. The port return loss is lower than $-15.8 \mathrm{~dB}$ up to $200 \mathrm{GHz}$ while the overall sensitivity is higher than $1.07 \mathrm{mV} / \mathrm{mW}$. The output voltage increases with the input power linearly, and the embedded sensor is almost independent of the microwave frequency. In future works, the fabrication of the proposed sensor and measurement results will be reported. Furthermore, a 3D model of the proposed sensor will be given to describe the fabricated sensor and assist sensor optimization.

Author Contributions: The authors contributed equally to this work.

Funding: This research received no external funding.

Conflicts of Interest: The authors declare no conflict of interest.

\section{References}

1. Yan, J.; Yi, Z.; Liao, X. High dynamic range microwave power sensor with thermopile and curled cantilever beam. Electron. Lett. 2015, 51, 1341-1343, doi:10.1049/el.2015.1665.

2. Dehe, A.; Fricke-Neuderth, K.; Krozer, V. Broadband Thermoelectric Microwave Power Sensors using GaAs Foundry Process. In Proceedings of the 2002 IEEE MTT-S International Microwave Symposium Digest (Cat. 
No.02CH37278), Seattle, WA, USA, 2-7 June 2002; Volume 3, pp. 1829-1832, doi:10.1109/mwsym.2002.1012218.

3. Yi, Z.; Liao, X. 3D Model of the Thermoelectric Microwave Power Sensor by MEMS technology. In Proceedings of the 2015 IEEE SENSORS, Busan, Korea, 1-4 November 2015; Volume 1, pp. 1-4.

4. Zhang, Z.; Guo, Y.; Li, F.; Gong, Y.; Liao, X. A Sandwich-Type Thermoelectric Microwave Power Sensor for GaAs MMIC-Compatible Applications. IEEE Electron Device Lett. 2016, 37, 1639-1641, doi:10.1109/led.2016.2619380.

5. Graf, A.; Arndt, M.; Gerlach, G. Seebeck's effect in micromachined thermopiles for infrared detection. A review. Est. J. Eng. 2007, 13, 338-353.

6. Dibra, D.; Stecher, M.; Lindemann, A.; Lutz, J.; Kadow, C. Seebeck difference-temperature sensors integrated into smart power technologies. In Proceedings of the 2008 20th International Symposium on Power Semiconductor Devices and IC's, Barcelona, Spain, 14-18 June 2009; pp. 216-219, doi:10.1109/ispsd.2009.5158040.

7. Weimann, N.G.; Stoppel, D.; Schukfeh, M.I.; Hossain, M.; Al-Sawaf, T.; Janke, B.; Doerner, R.; Sinha, S.; Schmückle, F.-J.; Krüger, O.; et al. SciFab-A wafer-level heterointegrated InP DHBT/SiGe BiCMOS foundry process for mm-wave applications. Phys. Status Solidi 2016, 213, 909-916, doi:10.1002/pssa.201532549.

8. Stoppel, D.; Ostermay, I.; Hrobak, M.; Shivan, T.; Hossain, M.; Reiner, M.; Thiele, N.; Nosaeva, K.; Brahem, M.; Krozer, V.; et al. NiCr resistors for terahertz applications in an InP DHBT process. Microelectron. Eng. 2019, 208, 1-6, doi:10.1016/j.mee.2019.01.007.

9. Dehe, A.; Pavlidis, D.; Hong, K.; Hartnagel, H. InGaAs/InP thermoelectric infrared sensor utilizing surface bulk micromachining technology. IEEE Trans. Electron Devices 1997, 44, 1052-1059, doi:10.1109/16.595931.

Publisher's Note: MDPI stays neutral with regard to jurisdictional claims in published maps and institutional affiliations.

(C) 2020 by the authors. Licensee MDPI, Basel, Switzerland. This article is an open access article distributed under the terms and conditions of the Creative Commons Attribution (CC BY) license (http://creativecommons.org/licenses/by/4.0/). 